\title{
A COMPARATIVE STUDY OF INTRAMUSCULAR BUPRENORPHINE AND MORPHINE IN THE TREATMENT OF CHRONIC PAIN OF MALIGNANT ORIGIN
}

\author{
MOGENS KJAER ${ }^{1 *}$, HANS HENRIKSEN ${ }^{2}$ \& JULIE KNUDSEN ${ }^{2}$ \\ ${ }^{1}$ Radiumstation, Finseninstitute, Copenhagen, Denmark and \\ ${ }^{2}$ Department of Anesthesiology, Finseninstitute, Copenhagen, Denmark
}

1 Twenty-seven patients with moderate to severe chronic pain of malignant origin received buprenorphine $(0.3 \mathrm{mg})$ and morphine $(10 \mathrm{mg})$ intramuscularly in a double-blind, single dose within patient study.

2 Efficacy analysis demonstrated no significant differences in the peak analgesic effects or in the time to reach these effects. However, buprenorphine had a significantly longer duration of action than morphine.

3 Sedation was the most frequent unwanted effect with a similar incidence following each treatment. Buprenorphine was associated with a significantly higher incidence, greater severity, earlier onset, and longer duration of dizziness, nausea and vomiting than morphine.

4 Following both treatments there were small but significant decreases in pulse rate, blood pressure, and respiratory rate.

\section{Introduction}

Buprenorphine is a newly developed derivative of the opium alkaloid thebaine acting as an agonistantagonist on the opiate receptor system. It has undergone rather extensive clinical testing as an analgesic in postoperative pain (Downing et al., 1977; Harcus et al., 1979; Hovell, 1977; Hovell \& Ward, 1977; Kamel \& Geddes, 1978; Kay, 1978; Tigerstedt \& Tammisto, 1980), and for chest pain in patients with suspected myocardial infarction (Hayes et al., 1979). Only limited information exists as to the effect of buprenorphine in cancer pain.

Ostrowski \& Jackson (1978) treated 24 patients in an open phase 2 trial with intramuscular injections of $0.3 \mathrm{mg}$ buprenorphine. Although detailed data were not reported the authors were impressed by the long duration of action lasting up to $24 \mathrm{~h}$ after a single dose. Two open phase 2 studies of sublingual

* Present address: Department of Oncology R., Copenhagen County Hospital at Herlev, Herlev Ringvej, DK2730 Herlev, Denmark. buprenorphine have also demonstrated satisfactory analgesia, and long duration of action (Adriaensen \& van de Walle, 1976; Robbie, 1979).

Summarizing existing clinical data on buprenorphine, two findings stand out:

(1) The long duration of action compared to conventional opiates.

(2) The lower addiction potential compared to other commonly used narcotics (Jasinski et al., 1978).

In our search for more effective analgesics in cancer patients we therefore decided to conduct a doubleblind, single dose, within patient comparison of buprenorphine and morphine following intramuscular administration.

The purpose of the study was to compare the analgesic activity, duration of action, incidence of unwanted effects, and the effect on vital signs after administration of the two drugs in patients suffering from moderate to severe chronic pain of malignant origin. 


\section{Methods}

Twenty-seven patients suffering from moderate to severe chronic cancer pain, 13 men and 14 women, mean age 60 years, range $41-71$ years, were admitted to the study. All patients had histologically proven and often heavily treated malignant disease in a relatively advanced stage.

The site of the primary tumour was: lung 12 cases, breast 7 cases, female genital system 4 cases, head and neck 3 cases, and œesophagus 1 case.

None of the patients had previously received regular doses of narcotics. The basis for selection of patients to the study was persistent pain where aspirin, dextropropoxyphene or paracetamol were no longer effective in controlling the pain.

All patients gave informed consent to participate in the study and agreed to spend at least 3 full days in hospital. Patients with severe renal damage (serum creatinine $\geq 120 \mu \mathrm{mol} / \mathrm{l}$ ), and severe hepatic damage (serum bilirubin $\geq 17 \mu \mathrm{mol} / \mathrm{l}$, plasma aspartate aminotransferase $\geq 50 \mathrm{U} / \mathrm{l}$, plasma alkaline phosphatase $\geq 275 \mathrm{U} / \mathrm{l}$, plasma lactate dehydrogenase $\geq$ $450 \mathrm{U} / \mathrm{l})$ were not included in the study. Neither were patients with marked ventilatory impairment or persistent mental confusion. The general and mental condition of the patients was such that they were ambulatory and able to cooperate verbally in the assessment of their pain and general condition during the study.

\section{Study medication}

Individual treatments were supplied in identical coded ampoules $(1 \mathrm{ml})$ containing either buprenorphine $(0.3 \mathrm{mg})$ or morphine $(10 \mathrm{mg})$. Each treatment pack consisted of two ampoules labelled $A$ and $B$ which were administered in alphabetical order. The order of treatments were randomized both within and between patients. Thirteen patients received buprenorphine and 14 patients morphine as the first injection.

\section{Evaluation of study medication}

All assessment and recordings were undertaken by the same trained nurse observer for all patients in the study. The first injection was given at $07.30 \mathrm{~h}$. Data were recorded prior to $(0)$, and at $0.25,0.5,1,1.5,2$, $3,4,5$ and $6 \mathrm{~h}$ following administration. Parameters followed for each patient are shown in Table 1 . Moreover, pulse rate, systolic and diastolic blood pressure, and respiratory rate were recorded at each observation time. For 14 patients recordings at 7 and $8 \mathrm{~h}$ were available. The second injection was administered $24 \mathrm{~h}$ after the first, and all recordings were repeated.
Table 1 Variables followed and codes used in patient assessment

\begin{tabular}{|c|c|}
\hline $\begin{array}{l}\text { Pain intensity } \\
\text { None } \\
\text { Slight } \\
\text { Moderate } \\
\text { Severe }\end{array}$ & $\begin{array}{c}\text { Score } \\
0 \\
1 \\
2 \\
3\end{array}$ \\
\hline $\begin{array}{l}\text { Pain relief } \\
\text { Complete } \\
\text { Good } \\
\text { Moderate } \\
\text { Slight } \\
\text { None }\end{array}$ & $\begin{array}{l}4 \\
3 \\
2 \\
1 \\
0\end{array}$ \\
\hline $\begin{array}{l}\text { Degree of sedation } \\
\text { Alert } \\
\text { Mildly drowsy } \\
\text { Moderately drowsy } \\
\text { Asleep }\end{array}$ & $\begin{array}{l}0 \\
1 \\
2 \\
3\end{array}$ \\
\hline $\begin{array}{l}\text { Severity of side effects } \\
\text { Mild } \\
\text { Moderate } \\
\text { Severe }\end{array}$ & $\begin{array}{l}1 \\
2 \\
3\end{array}$ \\
\hline $\begin{array}{l}\text { Side effects evaluated } \\
1 \text { Dizzy } \\
2 \text { Euphoria } \\
3 \text { Nausea } \\
4 \text { Vomiting } \\
5 \text { Sweating } \\
6 \text { Blurred vision } \\
7 \text { Thirsty }\end{array}$ & $\begin{aligned} 8 & \text { Sedation } \\
9 & \text { Deep respiration } \\
10 & \text { Decreased memory } \\
11 & \text { Numbness of hands and feet } \\
12 & \text { Headache } \\
13 & \text { Feeling intoxicated } \\
14 & \text { Anxious } \\
15 & \text { Feeling remote }\end{aligned}$ \\
\hline
\end{tabular}

No analgesic or sedative was administered less than $6.5 \mathrm{~h}$ prior to study medication.

Drugs allowed during the test period were the following:

— aspirin $1000 \mathrm{mg}$, paracetamol $1000 \mathrm{mg}$, diazepam 5 mg.

All other medications were recorded.

\section{Efficacy analysis}

After termination of the study the following parameters were calculated:

pain intensity difference scores (PID) for each patient at each observation time were calculated by subtracting the pain intensity score at each observation time from the pain intensity score prior to drug administration.

The sum of pain intensity difference scores (SPID) was calculated by adding the product of each postadministration PID and the corresponding time interval (in hours) since the previous observation.

Total pain relief scores (TOTPAR) were calculated by 
adding the product of each pain relief score and the corresponding time interval (in hours) since the previous observation. In calculating the mean PID and pain relief score at each observation time, for those patients who were remedicated during the $8 \mathrm{~h}$ period, a PID of zero was assumed at all observation times after they were remedicated.

Seven patients in the buprenorphine group were remedicated before $8 \mathrm{~h}$ compared with ten patients in the morphine group.

The time to remedication was calculated for each patient. One patient was excluded from the study after one treatment because she had to undergo radiotherapy for bone metastases. This patient was excluded from all analyses. Another patient was remedicated by mistake and was excluded from the efficacy analysis.

\section{Statistical evaluation}

Mean PIDs and pain relief scores for each treatment were plotted against time. The maximum PID and pain relief score and the time to maximum PID and pain relief score were compared using the Wilcoxon matched-pairs signed-ranks test. SPIDs and TOTPARs were compared after adjustment for the predrug PID using an analysis of covariance. Moreover, the variable percentage SPIDs were calculated (Littlejohns \& Vere, 1981; Sunshine, 1980) and compared using a paired $t$-test. Times to remedication were compared between treatments and treatment order groups using the log transformation and an analysis of variance. Allowance was made for the effect of replication within the same subject.

For each of the vital signs parameters graphs of mean responses and mean differences from baseline (time 0 ) were plotted against time. Baseline values were compared between treatments and treatment order groups using an analysis of variance. Differences from baseline were compared between treatments, treatment order groups, and times using an analysis of variance. Allowance was made for the relationship between baselines and differences from baseline. Treatment means and standard errors at each assessment were calculated. Each analysis of variance contained a test for carry-over effects and for period differences.

The severity, time of onset, and duration of side effects after each treatment were compared using the Wilcoxon matched-pairs signed-ranks test.

\section{Results}

Comparison of the two groups of patients according to randomization sequence with regard to sex, age, and weight showed no significant differences.

\section{Efficacy}

The mean PIDs at each observation time following each drug treatment and the mean pain relief are shown in Figure 1. Initial pain intensities were com-
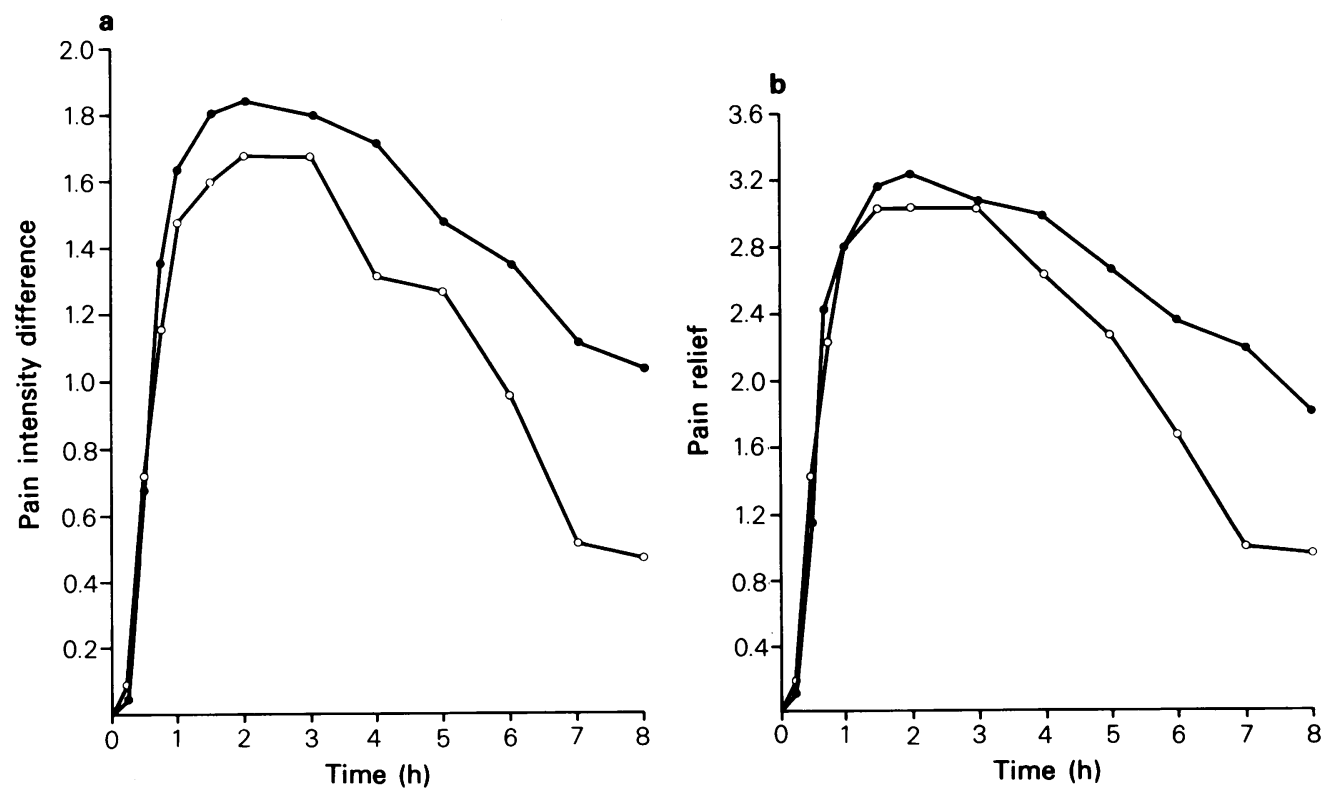

Figure 1 (a) Mean pain intensity difference and (b) mean pain relief at each observation time after intramuscular injection of $0.3 \mathrm{mg}$ buprenorphine $(O)$ and $10 \mathrm{mg}$ morphine $(O)$. 
parable at the beginning of each period. There were no differences in the maximum PIDs nor in the time to reach these scores following either treatment. Analysis of SPIDS showed that buprenorphine produced a marginally significant greater SPID than morphine $(P=0.06)$. Analysis of mean variable percentage SPIDs gave similar results $(P=0.08)$.

The results of the pain relief data showed a profile similar to the pain intensity results. However, TOTPARs observed following administration of buprenorphine were significantly greater than those following morphine $(P=0.014)$. There was evidence to suggest that greater pain relief was experienced by those patients with lower pain intensity $(P=0.08)$. The time to remedication after buprenorphine was significantly longer than that after morphine $(P=$ $0.05)$, the detransformed mean times being 10 and $8 \mathrm{~h}$ respectively.
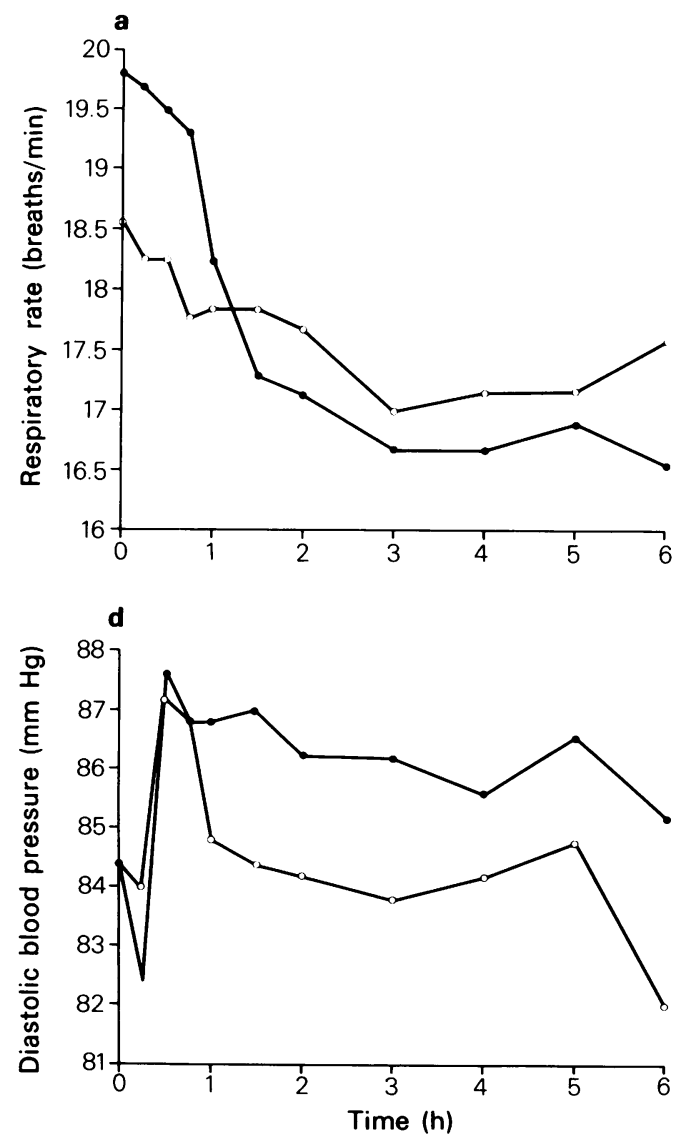

\section{Vital signs}

In Figure 2 are shown the mean values for each treatment at each observation time up to $6 \mathrm{~h}$ for pulse rate, systolic and diastolic blood pressure, and respiratory rate.

With both treatments significant decreases from baseline pulse rates were observed during the study becoming significant at $1 \mathrm{~h}$ with buprenorphine and at $3 \mathrm{~h}$ with morphine. No evidence of a return to baseline was observed with either treatment responses during the trial.

The changes in systolic blood pressure were similar following each treatment. A significant decrease from baseline occurred at the $0.75 \mathrm{~h}$ assessment time followed by little further change. Neither treatment caused any significant changes in diastolic blood pressure.
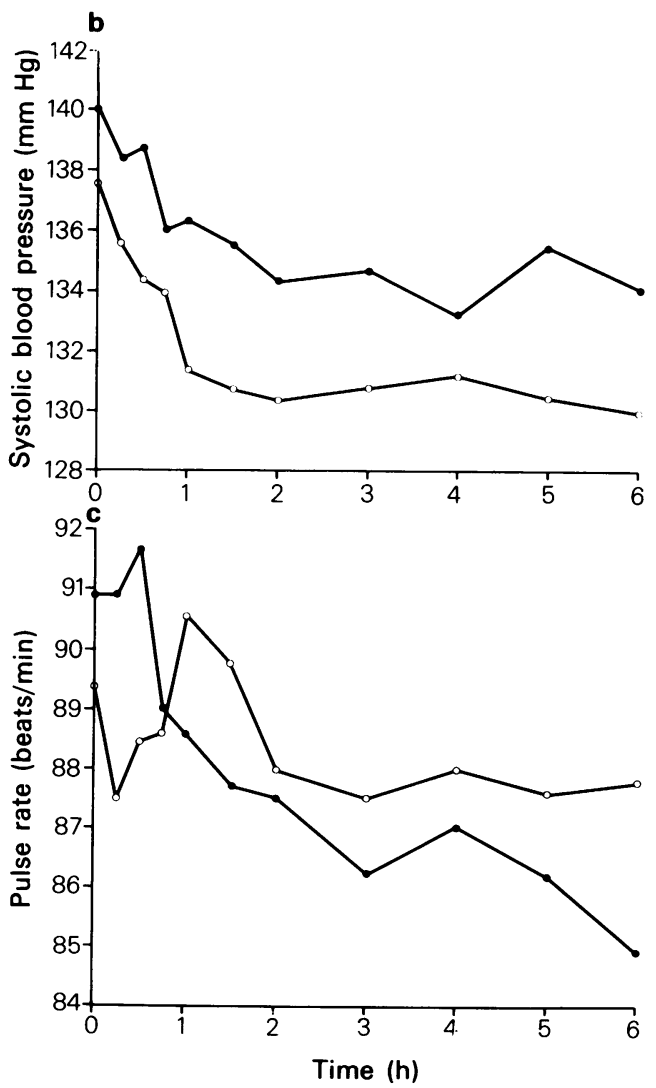

Figure 2 (a) Mean respiratory rate, (b) systolic, (c) diastolic blood pressure, and (d) pulse rate at each observation time after intramuscular administration of $0.3 \mathrm{mg}$ buprenorphine $(O)$ and $10 \mathrm{mg}$ morphine $(O)$. 
The mean baseline respiratory rate for patients receiving buprenorphine were significantly greater than the value prior to morphine $(P=0.01)$. Both drugs produced significant decreases in respiratory rate $0.75 \mathrm{~h}$ after injection which were maintained throughout the study period with the exception of $6 \mathrm{~h}$ after morphine administration when there was a return towards baseline. No carry-over effects were detected in any of the analyses performed.

\section{Side effects}

Sedation, dizziness, nausea, and vomiting were the four most common side effects. The severity, time of onset, and duration of these were compared after each treatment.

Sedation was reported by 22 patients. There were no differences between treatments in severity, time of onset, or duration experienced by the patients.

Dizziness was reported by 19 patients. Dizziness was more severe, of earlier onset, and lasted longer after buprenorphine than after morphine $(P<0.01$ on each comparison).

Nausea was reported by 12 patients, and vomiting by 11 patients. These were mainly present in the same patients. Nausea and vomiting were more severe, of earlier onset, and lasted longer following buprenorphine than following morphine $(P<0.05$ on each comparison).

Of the remaining side effects reported sweating (11 patients) and thirst (8 patients) were the only two experienced by more than 3 patients, and no differences between treatments were found.

\section{Discussion}

Our data confirm those of other studies where buprenorphine and morphine have been compared in patients with pain of non-malignant origin (Downing et al., 1977; Harcus et al., 1979; Hayes et al., 1979; Hovell, 1977; Hovell \& Ward, 1977; Kamel \& Geddes, 1978; Kay, 1978; Tigerstedt \& Tammisto,
1980). As such, buprenorphine seems to be an effective analgesic in cancer pain, the main advantage being the long duration of action resulting in fewer injections per day. The lower addiction potential compared to conventional narcotics (Jasinski et al., 1978) is of no practical importance in treating cancer patients with relatively advanced disease.

The effect on the vital signs as demonstrated in the present study was mild and of no practical importance.

It was demonstrated that buprenorphine was associated with a signficantly higher incidence, greater severity, earlier onset, and longer duration of dizziness, nausea, and vomiting than morphine. Cancer patients with chronic pain are often in a generally bad condition with weight loss, fatigue, decreased ability to eat, vomiting, and nausea as the result of their disease and its possible treatment (chemotherapy, radiotherapy etc.). Therefore, side effects which might be acceptable under other circumstances may in these patients lead to further deterioration of their general condition. Seen from this point of view it is our impression that the analgesic advantages of buprenorphine are outweighed by its more severe side effects.

On the other hand it is a general experience that side effects from narcotics commonly tend to subside with repeated use. It is therefore possible that chronic administration of buprenorphine will reduce the side effects, and also that the sublingual administration is useful in this respect. Further investigations regarding analgesia after repeated administrations and after oral use should therefore be conducted with buprenorphine in order to establish the role of this drug as an analgesic in cancer patients.

The authors want to thank the Clinical Sciences Department, Pharmaceutical Division, Reckitt \& Colman for the supply of drugs and the statistical evaluation of the results. Moreover, we want to thank our nurse observer Birgit Puggaard for her patient and careful registration of all pertinent assessment data.

\section{References}

ADRIAESEN, H. \& van de WALLE, J. (1976). Clinical use of buprenorphine in chronic administration. Acta anaesth. belg., 27, 187-191.

DOWNING, J.W., LEARY, W.P. \& WHITE, E.S. (1977). Buprenorphine: A new potent long-acting synthetic analgesic. Comparison with morphine. Br. J. Anaesth., 49, 251-255.
HARCUS, A.W., WARD, A.E. \& SMITH, D.W. (1979). Methodology of monitored release of a new preparation: buprenorphine. Br. med. J., 2, 163-165.

HAYES, M.J., FRASER, A.R. \& HAMPTON, J.R. (1979). Randomized trial comparing buprenorphine and diamorphine for chest pain in suspected myocardial infarction. Br. med. J., 2, 300-302. 
HOVELL, B.C. (1977). Comparison of buprenorphine, pethidine and pentazocine for the relief of pain after operation. Br. J. Anaesth., 49, 913-916.

HOVELL, B.C. \& WARD, A.E. (1977). Pain relief in the post-operative period: A comparative trial of morphine and a new analgesic buprenorphine. J. Int. med. Res., 5, $417-421$

JASINSKI, D.R., PEVNICK, J.S. \& GRIFFITH, J.D. (1978). Human pharmacology and abuse potential of the analgesic buprenorphine. Arch. gen. Psychiat., 35, 510-516.

KAMEL, M.M. \& GEDDES, I.C. (1978). A comparison of buprenorphine and pethidine for immediate postoperative pain relief by the i.v. route. Br. J. Anaesth., 50, 599-603.

KAY, B. (1978). A double-blind comparison of morphine and buprenorphine in the prevention of pain after operation. Br. J. Anaesth., 50, 605-609.
LITTLEJOHNS, D.W. \& VERE, D.W. (1981). The clinical assessment of analgesic drugs. Br. J. clin. Pharmac., 11, 319-332.

OSTROWSKI, M.J. \& JACKSON, A.W. (1978). Intramuscular buprenorphine-Clinical experience in its use for relieving pain due to malignant disease. Br. J. clin. Pract., 33, 286-293.

ROBBIE, D.S. (1979). A trial of sublingual buprenorphine in cancer pain. Br. J. clin. Pharmac., 7, 315S-317S.

SUNSHINE, A. (1980). Clinical evaluation of mild analgesics in post partum pain. Br. J. clin. Pharmac., 10, 335S-337S.

TIGERSTEDT, I. \& TAMMISTO, T. (1980). Double-blind multiple-dose comparison of buprenorphine and morphine in postoperative pain. Acta anaesth. scand., $24,462-468$.

(Revised October 30, 1981) 